\title{
Acoustic Design Criteria in Naturally Ventilated Residential Buildings: New Research Perspectives by Applying the Indoor Soundscape Approach
}

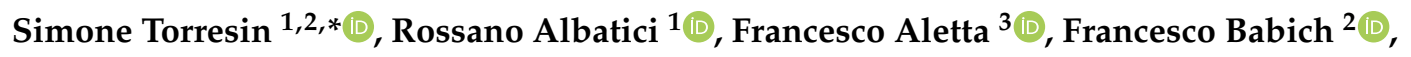 \\ Tin Oberman $^{3}(\mathbb{D})$ and Jian Kang ${ }^{3, *(D)}$ \\ 1 Department of Civil Environmental and Mechanical Engineering, University of Trento, Via Mesiano 77, \\ 38123 Trento, Italy; rossano.albatici@unitn.it \\ 2 Institute for Renewable Energy, Eurac Research, A. Volta Straße/Via A. Volta 13/A, 39100 Bolzano, Italy; \\ francesco.babich@eurac.edu \\ 3 UCL Institute for Environmental Design and Engineering, The Bartlett, University College London (UCL), Central \\ House, 14 Upper Woburn Place, London WC1H 0NN, UK; f.aletta@ucl.ac.uk (F.A.); t.oberman@ucl.ac.uk (T.O.) \\ * Correspondence: simone.torresin@eurac.edu (S.T.); j.kang@ucl.ac.uk (J.K.); Tel.: +39-0471055692 (S.T.)
}

Received: 9 October 2019; Accepted: 6 December 2019; Published: 10 December 2019

Featured Application: Providing a new research perspective for the development of acoustic requirements in naturally ventilated buildings and of façade control strategies enabling NV.

\begin{abstract}
The indoor-outdoor connection provided by ventilation openings has been so far a limiting factor in the use of natural ventilation (NV), due to the apparent conflict between ventilation needs and the intrusion of external noise. This limiting factor impedes naturally ventilated buildings meeting the acoustic criteria set by standards and rating protocols, which are reviewed in this paper for residential buildings. The criteria reflect a general effort to minimize noise annoyance by reducing indoor sound levels, typically without a distinction based on a ventilation strategy. Research has developed a number of solutions, discussed here, that try to guarantee ventilation without compromising façade noise insulation, but, currently, none have been adopted on a large scale. This concept paper highlights the main limits of the current approach. First, a fragmented view towards indoor environmental quality has not included consideration of the following acoustic criteria: (i) how buildings are designed and operated to meet multiple needs other than acoustical ones (e.g., ventilation, visual, and cooling needs) and (ii) how people respond to multiple simultaneous environmental factors. Secondly, the lack of a perceptual perspective has led acoustic criteria to neglect the multiple cognitive and behavioral factors impinging on comfort in naturally ventilated houses. Indeed, factors such as the connection with the outside and the sense of control over one's environment may induce "adaptive acoustic comfort" opportunities that are worth investigating. The mere use of different sound level limits would not be enough to define criteria tailored to the complex user-building interaction that occurs under NV conditions. More holistic and human-centered approaches are required to guarantee not only neutrally but even positively perceived indoor acoustic environments. For this reason, this paper considers this apparent conflict from a soundscape viewpoint, in order to expose still unexplored lines of research. By underpinning a perceptual perspective and by contextualizing it, the indoor soundscape approach provides a framework capable of overcoming the limits of the traditional noise control approach. This could provide the opportunity to foster a wider adoption of $\mathrm{NV}$ as a passive design strategy that enhances user health and well-being, while enabling low-cost, and low-energy cooling and ventilation, thereby contributing to current climate change challenges.
\end{abstract}

Keywords: indoor soundscape; natural ventilation; indoor environmental quality; acoustic design; residential building; alliesthesia; salutogenesis 


\section{Introduction}

During the last decade, thermal comfort research has seen a revival of natural ventilation (NV) as a passive design strategy to reduce cooling and ventilation energy demand [1,2], while providing pleasant thermal environments [2-6] and reducing the possibility of sick building syndrome [7,8]. NV uses temperature differences or wind pressure differentials to supply and remove air across ventilation openings to and from indoor spaces [9], without the adoption of mechanical systems to drive air movement (e.g., fans). The successful implementation of NV depends on several factors, such as the implemented ventilation strategy [10], the configuration of ventilation devices [11,12], the building floor plan [13], the characteristics of the neighboring buildings [14], the local climate [4,15], the outdoor air quality [1,16,17], and the external acoustic environment [18]. In addition, as a consequence of building users' needs and lifestyle changes (e.g., people spending more and more time out of home) the successful management and control of passive design solutions such as NV could depend on their effective integration into home automation systems, eventually controlled by sensor-driven building management systems. When such constraints make NV not suitable as the only ventilation strategy, $\mathrm{NV}$ could be combined with mechanical ventilation, thus referring to "mixed-mode" ventilation.

Windows and other ventilation openings constitute the main interfaces between outdoor and indoor environments. The indoor-outdoor connection they provide has been, so far, a major limiting factor in the use of NV due to the conflict between ventilation needs and the intrusion of external noise, which impedes naturally ventilated buildings from meeting background noise limits set by acoustic standards, building design regulations and rating protocols. As a response, for a long time, research has been developing a number of solutions that try to guarantee ventilation without compromising façade noise insulation [19-24]. Each of them presents advantages and disadvantages, but, up to the now, none has taken hold on large scale.

Attempts to block out external sounds while allowing for ventilation and silent indoor environments reflect the traditional noise control engineering approach, where sound is considered to be a "waste", inherently unwanted (i.e., noise) and as such to be reduced, regardless of its meaning, and its temporal or spectral characteristics. Perceptual outcomes of noise have been mainly evaluated in terms of resulting annoyance, being among the most relevant health issues caused by noise exposure [25]. Exposure-response relationships between noise levels and the percentage of highly annoyed residents have been derived for road traffic, railway, aircraft, and wind turbines [26]. Several annoyance models have been developed to predict total annoyance due to multiple simultaneous sources (e.g., model of energy summation, independent effects, energy difference, and dominant source). Such models are psychophysical if they are based on sound pressure level metrics, or perceptual if they are built on partial annoyance models. Their predictive powers have been compared through several studies, both in laboratory conditions and from social survey data, and extensive description and discussion can be found in the literature [27-30]. Annoyance models for single or combined sources have typically focused on different disturbing source types, such as: road traffic [28,29,31-36], railways [37,38], tramways [35,39], industrial noise [27-29,31,40,41], and aircraft noise [36,42]. Consequently, little is said about "wanted" sounds or sounds of preference.

Differently, soundscape research integrates noise control engineering approaches with physical, social, and psychological approaches to reach a holistic characterization of the acoustic environment, its perceived dimensions, and its health outcomes. According to the soundscape approach, sounds are differentiated based on people perception, experience, and understanding of the acoustic environment, in context [43]. In this perspective, sounds can be unwanted or wanted, and as such a "resource" to be exploited for generating positive indoor soundscapes according to people preference [44]. As such, the soundscape framework reinforces the need to prevent "noise" exposure, as a serious public health issues, and encourages "sound" exploitation to foster less annoying, as well as more comfortable environments, in line with a salutogenic approach to the building design [45,46].

The novelty of this concept paper is represented by the application of the indoor soundscape approach to the NV context. This means valuing sounds provided and filtered by ventilation openings 
through the application of soundscape assessment methods, in order to tackle the apparent conflict between acoustic comfort and NV from a different, perceptual view. The main goal is to derive future directions of research that may be possibly worth exploring, by providing a new research perspective for the development of acoustic requirements in naturally ventilated buildings and façade control strategies enabling NV.

The analysis, for this paper, follows the structure which is graphically represented in Figure 1, where the sections composing the main body of this paper are indicated. Methodologically, this concept paper provides, at first, context on (i) the approach that will be applied, by briefly introducing the soundscape concept and the recent trends in indoor soundscape research and (ii) the research field where such an approach could be applied, that is, acoustic comfort in naturally ventilated residential buildings. To this aim, acoustic criteria required for naturally ventilated residential buildings are reviewed, and a summary of the façade noise control solutions developed so far to meet those criteria is provided.

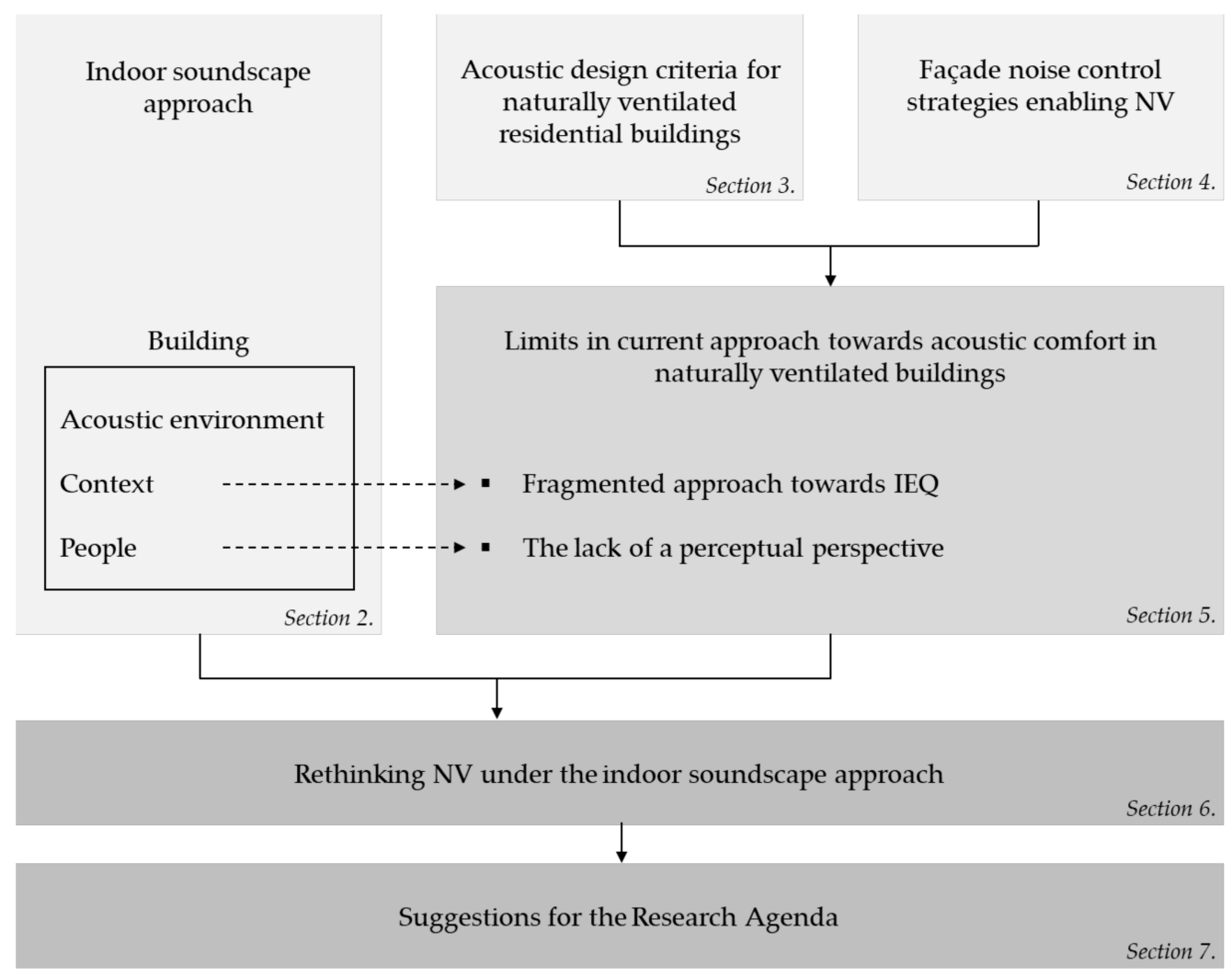

Figure 1. Graphical representation of the concept paper's structure.

The underpinning research questions are:

- What is the conceptual framework of indoor soundscape?

- What are the limits in the current approach towards acoustic comfort in naturally ventilated buildings?

Finally, the indoor soundscape approach will be tuned to the NV context, with the aim of answering the main research question of the study:

- How can the highlighted limits be overcome by the application of the indoor soundscape approach to the NV context?

This will derive future directions for research that could possibly be worth exploring in future field or laboratory investigations. 


\section{Indoor Soundscape Approach}

Soundscape definition underpins three main pillars that are the "acoustic environment", "people" and the "context" where the perception occurs. The concept was originally developed from studies conducted at an urban scale and in outdoor spaces, with the aim of shifting the focus from the negative to the positive effects of environmental sounds [47,48]. Standard ISO/TS 12913-2:2018 requires the integration through triangulation of multiple methods (soundwalks, questionnaires, guided interviews, non-participatory observations, and binaural measurements) for a holistic assessment of the acoustic experience, in context [49]. Nevertheless, a gap exists in linking perceptual metrics to acoustic or psychoacoustic measurements and, at the current stage, a straightforward characterization of a soundscape as positive is only possible through measurements by people. For this reason, the soundscape research community is putting great effort into the definition of indices able to objectively describe soundscapes, thus integrating or even replacing decibel-based metrics to reflect human comfort levels [48].

The soundscape concept has been recently applied to buildings and built indoor spaces, in order to characterize how people perceive, experience, and understand the indoor acoustic environment in the context of their working, living or leisure environments [50]. Indeed, the building itself plays a fundamental role in defining the acoustic environment, the people-related and contextual factors in the indoor soundscape concept, because, depending on its geometry and materials, outdoor sounds are filtered and the indoor acoustic environment is shaped, and depending on its function, users' expectations and needs are built.

Soundscape assessment methods, as defined by ISO/TS 12913-2:2018 technical specifications, have been mainly derived from listening tests playing outdoor sounds and it is not clear whether they are equally valid indoors [51]. If research on indoor soundscape is still at its embryonic stage, a general model for indoor soundscapes has been proposed, based on three main concepts that are "acoustical variables", "contextual factors", and "architectural factors" [52-55]. With reference to residential buildings, factors influencing indoor soundscapes have been recently reviewed and proposed as reference [51]. They include factors properly related to the acoustic environment (e.g., sound level, spectral content, roughness, loudness, fluctuation strength, and sound type), urban context and building characteristics, personal traits, socioeconomic features, situational circumstances, and environmental conditions [51]. General assessment methodologies for indoor soundscapes were investigated by several studies, such as questionnaires [56] or sound walks [57,58], also integrated into post-occupancy evaluations [54]. In residential buildings, questionnaires and guided interviews have been the assessment methods most commonly used to capture people's perception, whereas the adoption of soundwalks and non-participatory behavioral studies appears to be limited in an indoor context and need further investigation [51]. As regards the application of the semantic differential method for a subjective evaluation of indoor soundscapes, nine adjective pairs were proposed to describe three main perceptual dimension of sound ("evaluation", "potency", and "activity") in indoor and outdoor environments [59]. Methods such as "grounded theory" coupled with interviews have been specifically investigated in the field of indoor soundscapes, to systematically extract information on subjective perception from qualitative data gathered during questionnaires or interviews [60-62]. Several studies have addressed the perception of acoustic environments in specific building types, such as: residential buildings [51,57,63], offices [60,64], libraries [53,65], care facilities [66-68], study spaces [69], historical buildings [61,62], restaurants [70], shopping malls [71,72], and public transport spaces [73]. Table 1 provides insight into these selected studies. Information is given about the following:

- The building type, object of investigation (i.e., residential, office, library, care facility, study space, historical buildings, restaurant, shopping mall, and public transport space);

- Soundscape data collection methods used to capture perceptual data (i.e., soundwalk, interview, and questionnaire); 
- Sound levels and metrics used to describe the acoustic environment (i.e., A-weighted, C-weighted and Z-weighted equivalent continuous sound pressure level $\mathrm{L}_{\text {Aeq }}, \mathrm{L}_{\mathrm{Ceq}}, \mathrm{L}_{\text {Zeq }}$, loudness $\mathrm{N}$, sharpness $S$, roughness $R$, fluctuation strength $F$, reverberation time $T$, weighted standardized level difference $\mathrm{D}_{\mathrm{nT}, \mathrm{w}}$, weighted standardized impact sound pressure level $\mathrm{L}^{\prime}{ }_{\mathrm{nT}, \mathrm{w}}$, and speech transmission index STI);

- Data related to contextual characterization (i.e., sociocultural, socioeconomic, demographic, behavioral, architectural, and usage factors, number of persons, average meal price, food style, duration of stay, and activity).

Table 1. Indoor soundscape studies: Building type, data collection methods for perceptual outcomes, metrics for the characterization of the acoustic environment, and contextual data are reported. Objective acoustic data are sometimes reported by studies only for descriptive purposes.

\begin{tabular}{|c|c|c|c|c|}
\hline Reference & Building Type & $\begin{array}{l}\text { Soundscape Data } \\
\text { Collection Method }\end{array}$ & Sound Measure & Contextual Measure \\
\hline Berglund and Nilsson [57] & Residential & Soundwalk & $\mathrm{L}_{\mathrm{Aeq}, 30 \mathrm{~s}}$ & - \\
\hline $\begin{array}{c}\text { Mohamed and Dokmeci } \\
\text { Yorukoglu [63] }\end{array}$ & Residential & Questionnaire & - & $\begin{array}{c}\text { Sociocultural, } \\
\text { demographic, } \\
\text { architectural, and usage } \\
\text { factors }\end{array}$ \\
\hline Acun and Yilmazer [60] & Office & Interview & $\mathrm{L}_{\text {Aeq }}$ & - \\
\hline Ma and Shu [64] & Office & Questionnaire & $\mathrm{L}_{\text {Aeq }}$ & - \\
\hline $\begin{array}{c}\text { Dokmeci Yorukoglu and } \\
\text { Kang [53] }\end{array}$ & Library & - & $\mathrm{L}_{\text {Aeq, }}, \mathrm{N}$ & $\begin{array}{l}\text { Number of persons, } \\
\text { spatial, and architectural } \\
\text { factors }\end{array}$ \\
\hline Xiao and Aletta [65] & Library & Soundwalk & $\mathrm{L}_{\text {Aeq }}$ & - \\
\hline Aletta et al. [66] & Care facility & Questionnaire & $\begin{array}{c}\mathrm{L}_{\text {Aeq, }, 15 \min }, \mathrm{N}_{15 \min }, \\
\mathrm{T}_{20}\end{array}$ & Number of persons \\
\hline Mackrill et al. [67] & Care facility & Interview & - & - \\
\hline Thomas et al. [68] & Care facility & Interview & $\begin{array}{c}\mathrm{L}_{\mathrm{Aeq}, 15 \mathrm{~min}} \\
\mathrm{D}_{\mathrm{nT}, \mathrm{w}}(\mathrm{C}, \mathrm{Ctr}), \\
\mathrm{L}_{\mathrm{nT}, \mathrm{w}}^{\prime}\left(\mathrm{C}_{\mathrm{i}}\right) \\
\mathrm{T}_{500 \mathrm{~Hz}-2 \mathrm{kHz}}\end{array}$ & - \\
\hline Acun and Yilmazer [69] & Study space & Questionnaire & $\mathrm{L}_{\text {Aeq }}$ & - \\
\hline Acun and Yilmazer [61] & Historical building & Interview & $\mathrm{L}_{\text {Aeq }}, \mathrm{T}_{30}, \mathrm{STI}$ & - \\
\hline Acun and Yilmazer [62] & Historical building & Interview, Questionnaire & $\mathrm{L}_{\text {Aeq }}$ & - \\
\hline Lindborg [70] & Restaurant & Questionnaire & $\begin{array}{c}\mathrm{L}_{\text {Zeq }}, \mathrm{L}_{\text {Aeq }}, \mathrm{L}_{\mathrm{Ceq}}, \mathrm{N}, \\
\mathrm{S}, \mathrm{R}, \mathrm{F}\end{array}$ & $\begin{array}{l}\text { Number of persons, } \\
\text { prices, food style, and } \\
\text { architectural factors }\end{array}$ \\
\hline Chen and Kang [72] & Shopping mall & Questionnaire & $\mathrm{L}_{\text {Aeq }}, \mathrm{RT}, \mathrm{EDT}$ & $\begin{array}{l}\text { Duration of stay, activity, } \\
\text { and sociocultural factors }\end{array}$ \\
\hline Meng and Kang [71] & Shopping mall & Questionnaire & $\mathrm{L}_{\text {Aeq }}$ & $\begin{array}{l}\text { Socioeconomic and } \\
\text { behavioral factors }\end{array}$ \\
\hline Yilmazer and Bora [73] & $\begin{array}{l}\text { Public transport } \\
\text { space }\end{array}$ & Questionnaire & $\mathrm{L}_{\text {Aeq }}$ & - \\
\hline
\end{tabular}

If a variety of factors related and unrelated to the acoustic environment, besides sound level, were found to affect the perceptual response of building occupants, patterns between objectively measurable indices and subjective measures are in most cases difficult to recognize. Clearly, there is a long way to go before a fully functional indoor soundscape model is ready to be applied in the design of indoor environments and integrated into standardization [52,55], but the aim is clear: promoting the design of spaces that are positively perceived by building users. How to reach such a goal through NV will be the focus of Section 6. 


\section{Acoustic Design Criteria for Naturally Ventilated Residential Buildings}

The acoustic criteria to be met in building and building services design by architects, acousticians, and mechanical engineers are provided by several standards and technical guidelines. Among others, due to the intrusion of external noise, reference values for background noise levels are of particular concern for naturally ventilated buildings.

In order to extract reference limits that practitioners have to face when designing naturally ventilated buildings, a selection of internationally recognized standards and technical guidelines has been reviewed, with a focus on residential environments. Table 2 presents the following: (i) recommended background noise limits for residential buildings; (ii) sound sources to be considered in sound level assessment (e.g., indoor building service systems, outdoor sources); (iii) measurement conditions (e.g., windows open or closed); and (iv) tolerances allowed in the recommended limits, for specific cases. In particular, recommended noise limits are provided together with their metric (e.g., $\mathrm{L}_{\mathrm{Aeq}, \mathrm{T}}$ and $\mathrm{L}_{\mathrm{Max}}$ ), the period of the day considered for level evaluation (e.g., day or night periods, and reference hours, when available), and the specific indoor area where the limits apply (e.g., living room, and bedrooms). 
Table 2. Recommended background noise limits for residential buildings from standards and design guidelines, sound sources to be considered, measurement conditions, and tolerances allowed on the recommended limits.

\begin{tabular}{|c|c|c|c|c|}
\hline Reference & Background Noise Level Limits & Sound Sources Considered & Measurement Conditions & Tolerances \\
\hline BS-EN 16798-1:2019 [74] & $\begin{array}{l}\mathrm{L}_{\text {eq,nT, }} \leq 30,35,40 \mathrm{dBA} \text { for living rooms, corresponding to category I, II, IIII. } \\
\mathrm{L}_{\text {eq }, \mathrm{nT}, \mathrm{A}} \leq 25,30,35 \mathrm{dBA} \text { for bedrooms, corresponding to category I, II, III }\end{array}$ & $\begin{array}{l}\text { Continuous sources related to } \\
\text { building service systems. No } \\
\text { outdoor sources. }\end{array}$ & - & $\begin{array}{l}5 \text { to } 10 \mathrm{dBA} \text { occupants having } \\
\text { control over the operation of services } \\
\text { or windows. }\end{array}$ \\
\hline AS/NZS 2107:2016 [75] & 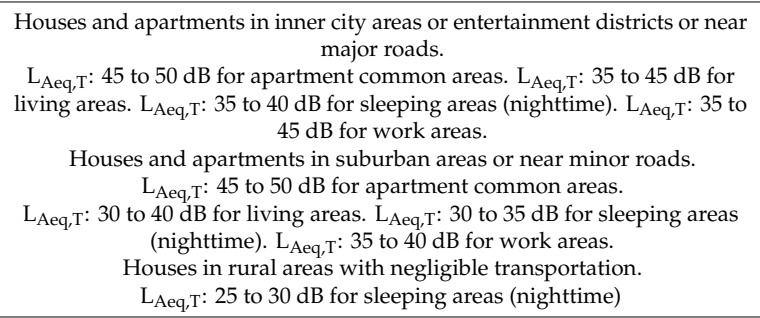 & $\begin{array}{l}\text { Steady-state or } \\
\text { quasi-steady-state sources. Not } \\
\text { for indoor spaces where the } \\
\text { operation of NV devices can } \\
\text { compromise design sound } \\
\text { levels. }\end{array}$ & $\begin{array}{l}\text { Windows open or closed, } \\
\text { depending on building } \\
\text { operating conditions. }\end{array}$ & - \\
\hline BS 8233:2014 [76] & $\begin{array}{c}\text { (day: } 07: 00-23: 00) . \\
\mathrm{L}_{\text {Aeq,16hr: }} 35 \mathrm{~dB} \text { for living room. } \mathrm{L}_{\text {Aeq,16hr: }} 40 \mathrm{~dB} \text { for dining room/area. } \\
\mathrm{L}_{\text {Aeq, } 16 h r:} 35 \mathrm{~dB} \text { for bedroom. } \\
\text { (night: } 23: 00 \text { to 07:00). } \\
\mathrm{L}_{\text {Aeq, }, 8 \mathrm{hr}:}: 30 \mathrm{~dB} \text { for bedroom }\end{array}$ & $\begin{array}{l}\text { Indoor and outdoor sources } \\
\text { (items such as fridges, freezers, } \\
\text { cookers and water heaters } \\
\text { turned off). Steady outdoor } \\
\text { sources. }\end{array}$ & $\begin{array}{l}\text { Windows or trickle vents open } \\
\text { or closed, depending on } \\
\text { building operating conditions. }\end{array}$ & - \\
\hline $\begin{array}{l}\text { WHO Guidelines for Community Noise } 1999 \\
\text { [77] }\end{array}$ & $\begin{array}{c}\text { (day: } 16 \mathrm{hr} \text { ). } \\
\mathrm{L}_{\text {Aeq }}: 35 \mathrm{~dB} \text { for dwelling, indoors. } \\
\text { (night: } 8 \mathrm{hr} \text { ). } \\
\mathrm{L}_{\mathrm{Aeq}}: 30 \mathrm{~dB} \text { inside bedrooms. } \mathrm{L}_{\mathrm{AMax}} \text {, fast: } 45 \mathrm{~dB} \text { inside bedrooms }\end{array}$ & - & - & - \\
\hline $\begin{array}{l}\text { ANSI/ASHRAE/ICC/USGBC/IES Addendum } \\
\text { o to ANSI/ASHRAE/USGBC/IES Standard } \\
\text { 189.1-2014-Standard for the Design of } \\
\text { High-Performance Green Buildings. Except } \\
\text { Low-Rise Green Buildings [78] }\end{array}$ & 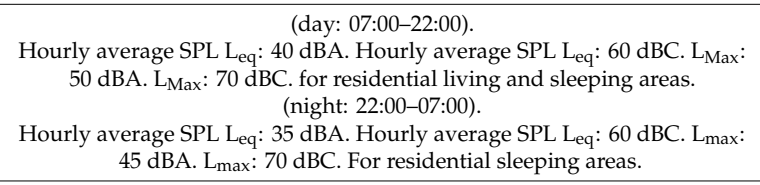 & $\begin{array}{l}\text { Indoor sources related to } \\
\text { building service systems and } \\
\text { outdoor sources }\end{array}$ & Closed windows & $\begin{array}{l}5 \text { or } 10 \mathrm{~dB} \text { on } \mathrm{L}_{\text {eq }} \text { depending on the } \\
\text { number of exterior events occurring } \\
\text { per day. } 10 \mathrm{~dB} \text { or without limitation } \\
\text { on } \mathrm{L}_{\text {max }} \text { depending on the number } \\
\text { of exterior events occurring per day. }\end{array}$ \\
\hline $\begin{array}{l}\text { Acoustics Ventilation and Overheating } \\
\text { Residential Design Guide (Draft for } \\
\text { consultation) [79] }\end{array}$ & $\begin{array}{c}\text { Traffic noise (only overheating condition reported): } \\
\text { (day: } 7: 00-23: 00) \\
\mathrm{L}_{\mathrm{A} \text { eq, } \mathrm{T}}: \leq 35 \mathrm{~dB},>35 \mathrm{~dB} \text { and } \leq 40 \mathrm{~dB},>40 \mathrm{~dB} \text { and } \leq 50 \mathrm{~dB},>50 \mathrm{~dB} . \\
\text { corresponding to risk category: negligible, low, medium, high } \\
\text { (night: } 23: 00-07: 00 \text { ) } \\
\mathrm{L}_{\mathrm{Aeq}, \mathrm{T}} \mathrm{:}: \leq 35 \mathrm{~dB},>35 \mathrm{~dB} \text { and } \leq 40 \mathrm{~dB},>40 \mathrm{~dB} \text { and } \leq 50 \mathrm{~dB},>50 \mathrm{~dB} \\
\text { corresponding to risk category: negligible, low, medium, high. Mechanical } \\
\text { sources (only overheating conditions reported): } \\
\text { Comfort criteria from CIBSE Guide A 2015, Table } 1.5 \text { with reference to } \\
\text { section 1.10.10 of CIBSE Guide A }\end{array}$ & $\begin{array}{l}\text { Traffic sources and building } \\
\text { service systems }\end{array}$ & - & - \\
\hline $\begin{array}{l}\text { GVA/15 CIBSE Guide A: Environmental } \\
\text { Design } 2015 \text { [80] }\end{array}$ & $\begin{array}{l}\text { NR: } 25 . \mathrm{L}_{\text {Aeq }} \leq 30 \mathrm{~dB} \text {. } \mathrm{L}_{\mathrm{Ceq}} \leq 55 \mathrm{~dB} \text { for bedrooms. } \\
\text { NR: } 30 \text {. } \mathrm{L}_{\text {Aeq }} \leq 35 \mathrm{~dB} \text {. } \mathrm{L}_{\mathrm{Ceq}} \leq 60 \mathrm{~dB} \text { for living rooms. } \\
\text { NR: } 40 \text { to } 45 . \mathrm{L}_{\text {Aeq }} \leq 45 / 50 \mathrm{~dB} \text {. } \mathrm{L}_{\mathrm{Ceq}} \leq 70 / 75 \mathrm{~dB} \text { for kitchen. }\end{array}$ & Building service systems & - & $\begin{array}{l}5 \mathrm{~dB} \text { depending on the specific } \\
\text { situation }\end{array}$ \\
\hline
\end{tabular}


In the case of residential buildings, standards and design guidelines provide the following: (i) reference values for overall internal sound levels generated by indoor and outdoor sources and (ii) limits for background noise generated by building services. Guidance is provided in terms of noise ratings or in terms of equivalent continuous sound pressure levels, $\mathrm{A}$ or $\mathrm{C}$ weighted, often normalized over a period $\mathrm{T}$ or with respect to reverberation time.

In all the standards and guidelines mentioned before, buildings are typically assumed to be mechanically ventilated $[74,75,78-80]$ and measurements must be performed with closed windows [78] or with window position according to the ventilation strategy $[75,76]$. Standard BS 8233:2014 recommends that whether guide values are met with closed windows, alternative ventilation systems exist [76]. Standard AS/NZS 2107:2016 specifies that the standard "is not intended for [ ... ] spaces inside buildings with essential features enabling ventilation, cooling or heating that when operated, compromise design sound levels and reverberation control, e.g., opening windows and/or doors for natural ventilation" [75]. Nevertheless, the standard provides different level ranges according to the type of external urban context surrounding the building (i.e., inner-city areas or entertainment districts, areas near major roads, suburban areas or areas near minor roads, and rural areas with negligible transportation). The WHO Guidelines for Community Noise implicitly refer to naturally ventilated spaces when reporting night indoor and outdoor noise level requirements for bedrooms, as outdoor levels have been fixed in order to allow people to sleep with open windows [77]. However, different indoor noise levels are not included according to the ventilation strategy. Standard 189.1-2014 (2017 addenda) allows for 5 or $10 \mathrm{~dB}$ tolerances in indoor noise levels depending on the daily frequency of high-noise exterior events that cause the excess sound pressure level [78]. A $5 \mathrm{~dB}$ relaxation in noise levels is also included in the CIBSE Guide A, in the case of particular situations [80]. Therefore, specific acoustic criteria for naturally ventilated buildings are not provided, but a tolerance is allowed by standard EN ISO 16798-1 for a short-term period in the case of control over window operation [74].

The draft Acoustics Ventilation and Overheating Residential Design Guide (hereinafter AVO guide), produced by the Association of Noise Consultants in the UK, allows for higher levels of indoor noise from transportation sources when higher ventilation rates are needed to mitigate overheating, for example, by window opening, based on the following assumptions: (i) overheating occurs only for short periods of the year, (ii) suboptimal acoustic conditions are bearable when counterbalanced by better indoor thermal and air quality conditions, and (iii) occupants are provided with some control over their environment $[79,81]$. However, as stressed by the AVO guide, this proposal is not supported by available research on human response to combined heat and noise. The AVO guide constitutes a proposal of an integrated framework to assess acoustic, ventilation, and overheating, in order to overcome the current incompatibility of assumptions between acoustic and mechanical designers. In fact, while the former considers windows being closed to control external sound access, the latter assumes windows being open for ventilation and overheating mitigation purposes. Thus, building occupants are eventually forced to choose whether to satisfy their acoustic or thermal and ventilation needs, without giving them the possibility of living in fully healthy and comfortable environments.

In addition to standards and design guidelines, a series of international building rating and certification systems has been reviewed. Building assessment protocols typically provide design criteria to be met in order to gain credits that, summed up, constitute the score reached by the building which corresponds to a certain certification level. Background noise level limits guiding the credit assignation are provided in Table 3, together with sound sources to be considered, measurement conditions, and allowed tolerances. 
Table 3. Reference background noise limits for residential buildings from building assessment protocols, sound sources to be considered, measurement conditions, and tolerances allowed on the reference limits.

\begin{tabular}{|c|c|c|c|c|}
\hline Reference & Background Noise Level Limits & Sound Sources Considered & Measurement Conditions & Tolerances \\
\hline $\begin{array}{l}\text { BREEAM International New } \\
\text { Construction [82] }\end{array}$ & No limit for residential buildings & - & - & - \\
\hline $\begin{array}{c}\text { Green Star-Design \& as built } \\
\text { v1.2 [83] }\end{array}$ & $\begin{array}{l}\text { Mechanically ventilated and mixed mode buildings: internal } \\
\text { ambient noise levels in residential lounge rooms and bedrooms } \\
\text { are no more than } 5 \mathrm{~dB}(\mathrm{~A}) \text { above the lower limit in the range } \\
\text { recommended by standard AS/NZS2107:2016 NV buildings: the } \\
\text { internal ambient noise levels must be no more than } 10 \mathrm{~dB}(\mathrm{~A}) \\
\text { above the lower limit in the range recommended by standard } \\
\text { AS/NZS 2107:2016 }\end{array}$ & $\begin{array}{l}\text { Indoor and outdoor sources } \\
\text { (building service systems, traffic } \\
\text { sources, industrial plants) }\end{array}$ & $\begin{array}{l}\text { In NV buildings all } \\
\text { measurements must be } \\
\text { performed with NV openings in } \\
\text { the open position. }\end{array}$ & - \\
\hline Home Quality Mark ONE [84] & $\begin{array}{c}\text { (day: 07:00-23:00) } \\
\mathrm{L}_{\text {Aeq, },}: 35 \mathrm{~dB} \text { for habitable rooms and kitchens. } \mathrm{L}_{\text {Aeq, } \mathrm{T}}: 35-45 \mathrm{~dB} \\
\text { for open plan rooms that a kitchen is part of } \\
\text { (night: } 23: 00-07: 00 \text { ) } \\
\mathrm{L}_{\text {Aeq, }}: 30 \mathrm{~dB} \text { for bedrooms. } \mathrm{L}_{\text {Aeq, } \mathrm{T}}: 35 \mathrm{~dB} \text { for kitchens and open } \\
\text { plan rooms that a kitchen is part of }\end{array}$ & $\begin{array}{l}\text { Indoor and outdoor sources, with } \\
\text { building service systems on } \\
\text { (extractor fan noise in the } \\
\text { measurements for } \\
\text { kitchens excluded) }\end{array}$ & $\begin{array}{c}\text { Internal noise level measured } \\
\text { with closed windows and open } \\
\text { trickle vents, if required for the } \\
\text { ventilation strategy. }\end{array}$ & $\begin{array}{l}3 \mathrm{~dB} \text { allowed for an } \\
\text { individual room }\end{array}$ \\
\hline $\begin{array}{l}\text { LEED v4.1 Residential single } \\
\text { family homes [ } 85]\end{array}$ & $35 \mathrm{dBA}$ for living areas; $45 \mathrm{dBA}$ for kitchens and baths & Building service systems & - & - \\
\hline $\begin{array}{l}\text { LEED v4.1 Residential BD+C } \\
\text { Multifamily homes [86] }\end{array}$ & $35 \mathrm{dBA}$ for living areas; $45 \mathrm{dBA}$ for kitchens and baths & Building service systems & - & - \\
\hline WELL v2 $[87,88]$ & $\begin{array}{l}\text { (day: } 07: 00 \text { to } 22: 00) \\
\mathrm{L}_{\mathrm{eq}}: 40,45,50 \mathrm{dBA} \text {. } \mathrm{L}_{\mathrm{eq}}: 65,70,75 \mathrm{dBC} \text {. } \mathrm{L}_{\mathrm{Max}}: 50 \text { to } 55 \mathrm{dBA} \text {. } \mathrm{L}_{\mathrm{Max}}: \\
75,80 \mathrm{dBC} \text { for residential living and sleeping areas, } \\
\text { corresponding to: } 3,2 \text {, and } 1 \text { credit points } \\
\text { (night: } 22: 00 \text { to } 24: 00 \text { ) } \\
\mathrm{L}_{\mathrm{eq}}: 35,40,45 \mathrm{dBA} \text {. Leq }: 60,65,70 \mathrm{dBC} \text {. } \mathrm{L}_{\mathrm{Max}}: 45 \text { to } 50 \mathrm{dBA} \text {. } \mathrm{L}_{\mathrm{Max}}: \\
70,75 \mathrm{dBC} \text { for residential sleeping areas, corresponding to: } 3,2 \text {, } \\
\text { and } 1 \text { credit points }\end{array}$ & $\begin{array}{l}\text { Indoor and outdoor sources } \\
\text { (building service systems included) }\end{array}$ & $\begin{array}{l}\text { Windows open or closed, } \\
\text { depending on building } \\
\text { operating conditions. }\end{array}$ & $4 \mathrm{~dB}$ on $\mathrm{L}_{\mathrm{eq}} 9 \mathrm{~dB}$ on $\mathrm{L}_{\mathrm{Max}}$ \\
\hline
\end{tabular}


Building rating systems generally provide reference values for indoor noise levels in residential buildings and such levels are typically derived from acoustic criteria for mechanical services. Noise limits refer to either (i) overall indoor noise or (ii) noise exclusively produced by HVAC systems $[85,86]$. In detail, more relaxed limits for naturally ventilated buildings are only included in the Green Star protocol [83]. Differently, the BREEAM protocol regulates indoor noise exposure indirectly through limits on airborne and impact sound insulation [82], thus, not referring to the ventilation strategy.

Measurements must be performed with window opening positions according to building operating conditions $[83,87,88]$ or with closed windows and open trickle vents, if required for the ventilation strategy [84].

A summary of noise control strategies employable in natural ventilated buildings to meet standard or design guideline specifications or to gain acoustic credits in rating protocols is provided in the following section.

\section{Façade Noise Control Strategies Enabling NV}

If treatments on the sound source (e.g., road traffic) are often impractical, controlling the sound path between the source and the receiver (i.e., building façade and ventilation openings) can be done through a correct site and building design. Available methods include, for example, a proper distribution of functions and infrastructures at urban scale; the optimal location and orientation of buildings; the use of external barriers, earth mounds or less-sensitive buildings to shield more sensitive ones; the correct collocation of functional areas inside buildings; and the positioning of ventilation openings as a function of the outdoor acoustic environment. However, constraints could limit the applicability of such measures (e.g., interventions in urbanized areas, on existing buildings, acoustic needs conflicting with other disciplines involved in urban planning, and building design, etc.), and building façade measures might then be the only feasible solution to control the sound transmitted through ventilation openings.

The research community is continuously committed to searching for new technologies and in improving existing ones, in order to allow for $\mathrm{NV}$ usage and to limit the access of external noise, in order to meet the requirements described in Section 2.

In the following paragraphs, available noise control strategies for enabling NV are presented. Here, solutions described in the two major reviews by De Salis et al., in 2002 [19] and Tang, in 2017 [20] are briefly summarized and integrated with references to the latest available studies, differentiating between passive, active, automation-based, and hybrid solutions.

\subsection{Passive Strategies}

External protrusions can be coupled with windows to shield from road traffic noise while allowing window opening for ventilation purposes. Solutions include horizontal lintels, vertical fins, eaves, louvers, and solar shadings (see Figure $2 \mathrm{a}-\mathrm{d}$ for a schematic representation). Their efficacy is generally limited and depends on the view angle of the road seen by the openings and on the presence of absorption material on them [20]. Indeed, reflections by protrusions can even worsen the acoustic conditions in the building façade, by screening some areas while directing reflections on others. Louvers are most effective at high frequencies, because of diffraction effects around the blades at low frequencies. Similar considerations apply to balconies (Figure 2i), whose acoustical protection effectiveness mainly depends on the application of sound absorption material on the ceiling and on the application of ceiling reflectors, designed and oriented on the basis of the elevation angle, source orientation, and distance. Parapet inclination and balcony depth are further factors that improve the acoustic attenuation. As observed by Tang, studies on façade protrusions usually have not taken city reverberation into account and performance is supposed to be reduced in the presence of street canyon effects [20]. 


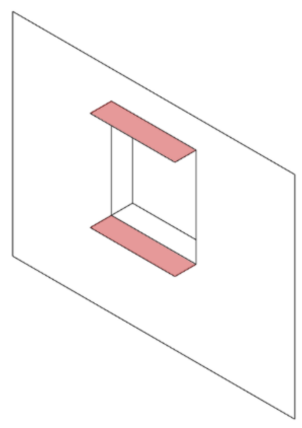

(a)

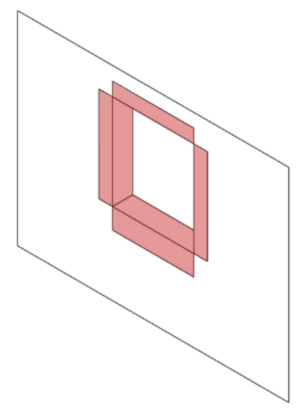

(e)

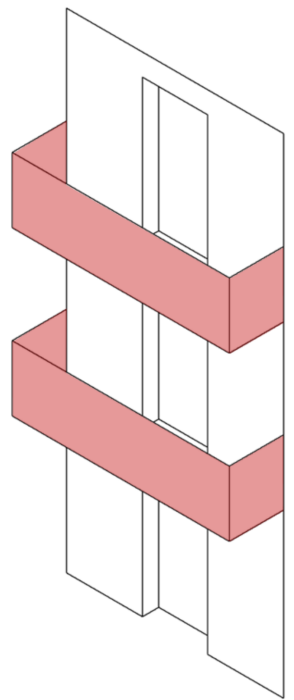

(i)

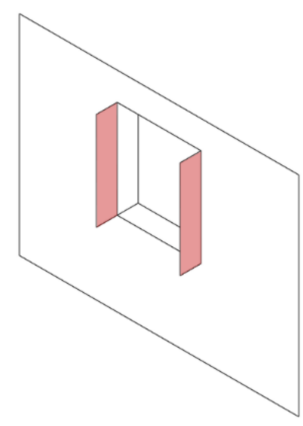

(b)

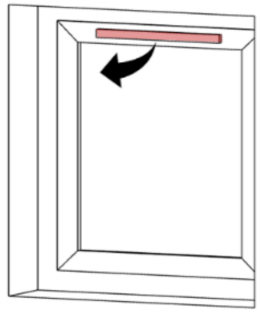

(f)

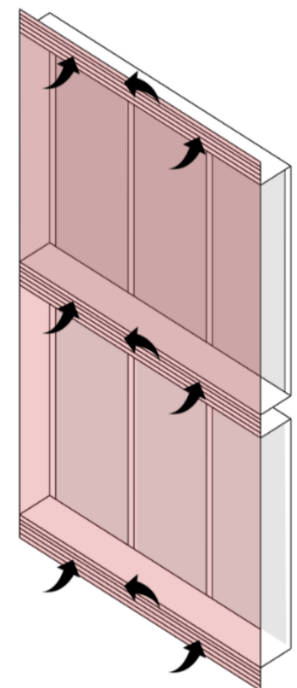

(j)

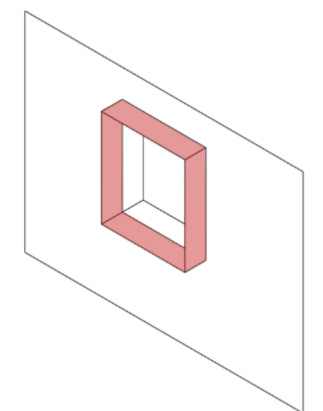

(c)

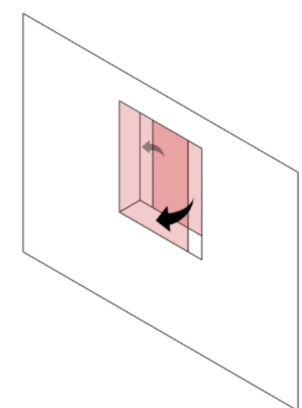

(g)

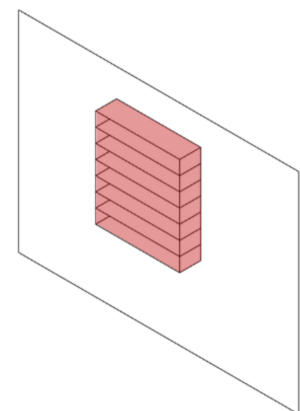

(d)

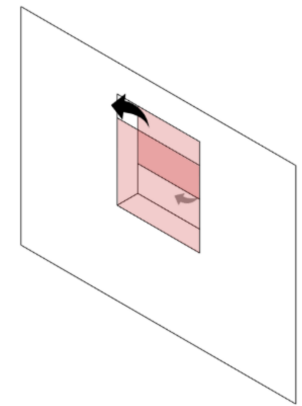

(h)

Figure 2. Schematic representation of passive strategies enabling natural ventilation (NV): (a) Horizontal lintels; (b) vertical fins; (c) eaves; (d) louvers or solar shadings; (e) resonators around ventilation opening; (f) trickle vents; (g) plenum window, horizontal type; (h) plenum window, vertical type; (i) balconies; and (j) double skin facades.

The application of reactive elements, such as quarter wave resonators around ventilation openings, has been investigated in the literature (Figure 2e). The strategy is efficient around the frequency to which the resonator is tuned, with limitations at low frequencies where the resonator would be impractically large. The main limitation of such a solution is the fact that to attenuate noise over a broad spectrum, multiple rows of resonators tuned at different frequency bands are required, resulting in a bulky device. Recently, Yu et al. studied a ventilation window designed by using resonant-chamber unit cells, made of transparent acrylic panels, with apertures on the front and rear surfaces, arranged 
in a plane to form an acoustic metasurface $[89,90]$. The transmission loss of the partition with the installed window prototype is reported to be above $20 \mathrm{~dB}$ in the 800 to $3150 \mathrm{~Hz}$ frequency range [90].

Trickle vents are openings usually integrated into the window frame and used to provide background ventilation in combination with other forms of ventilation (see Figure $2 \mathrm{f}$ for a schematic representation). Recently Biler et al. reviewed the performances of such devices and reported that their acoustic insulation can reach values of around $40 \mathrm{~dB}\left(\mathrm{D}_{\mathrm{n}, \mathrm{e}}\right)$ [91]. Notably, it must be observed that the ventilation performance depends on their correct usage by building occupants. The occupant survey conducted in Scotland by Sharpe et al. revealed that little occupant interaction occurred with such devices (i.e., trickle vents were in many cases always left closed) and window opening remained in many cases the preferred method for ventilation provision [92].

Plenum windows are double glazed structures with staggered air inlet and outlet, forming an air passage between the two window glass panes. Depending on the opening orientation, plenum windows can be of horizontal or vertical type (Figure $2 \mathrm{~g}, \mathrm{~h}$ ). Performance depend on the overlapping length of the two glazed layers, the opening sizes, the gap width, the sound incidence angle, and the relative orientation between the window and the sound source [20]. The insertion of sound absorbing material into the plenum (e.g., linings over the internal surfaces of the plenum window, transparent microperforated absorbers [93-95], or rigid circular cylinder arrays [96] ) can provide further acoustic improvement. However, modified ventilation windows could result in strongly reduced airflow rates.

$\mathrm{NV}$ double skin facades (DSFs) can be considered as plenum windows with larger dimensions (Figure 2j). In the study by Urban et al., in situ and laboratory measurements were performed on DSFs and on double glass structures [97]. The performance was reported to improve with increasing cavity widths, by adopting ventilation grids instead of open slots and by inserting absorption material.

\subsection{Active Strategies}

In addition to passive strategies, active noise control (ANC) solutions can be implemented in window openings to control the sound power transmitted through the aperture, thus, reducing the noise level in the indoor space (global control) or in part of it (local control). Transducers (e.g., loudspeakers) are required in the window opening to generate the so-called "anti-noise" that interferes destructively with the sound entering from the outside. Loudspeakers can be located on the boundary of the window opening or distributed over the entire aperture (see Figure $3 a, b$ for a schematic representation). A summary of performances derived from recent studies through boundary or distributed methods is provided by Lam et al. [98]. The minimum number of required sources is a function of the frequency upper bound and the incident angle [99]. When wavelengths are large in comparison to the opening size, a smaller number of sources is required, and the boundary layout can be effective [98]. However, diffraction effects occur at large wavelengths, degrading the performance of boundary solutions [99]. Whether the boundary layout is only effective at low frequencies, for small apertures, or for local control [100], the distributed layout can outperform at a cost of opening obstruction. As regards source positioning, better performances are reported with loudspeakers located in the middle of the wall width and distanced from the opening edge [99].

ANC is most effective in attenuating steady-state noises but feedback or feedforward controls can be implemented, able to respond to varying input stimuli $[19,101]$. It must be noticed that if the system is not perfectly tuned, ANC could become a source of additional unwanted sounds [19]. 


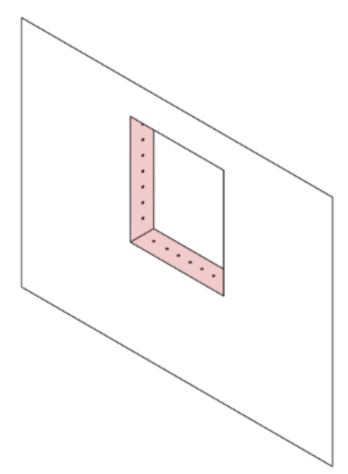

(a)

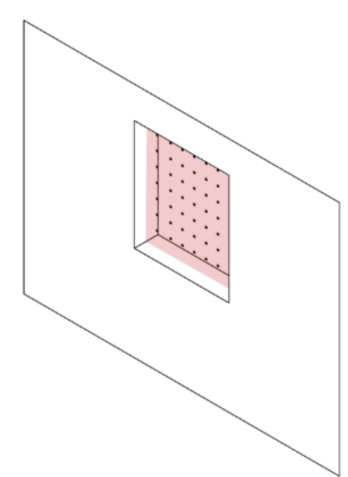

(b)

Figure 3. Schematic representation of active strategies enabling NV: (a) boundary layout and (b) distributed layout.

\subsection{Automation-Based Strategies}

Automation-based strategies are based on the automatic opening and closing of the ventilation apertures depending on outdoor acoustic conditions, typically defined by outdoor noise levels (see Figure 4 for a schematic representation). A sensor driven window automation was studied by Martin et al., allowing for automatic window closing as soon as a certain external noise level was reached [102]. Within their laboratory tests, subjects rated the closed and automatically closed windows as equally loud and annoying, but, in the latter case, ventilation was allowed in the case of favorable outdoor acoustic conditions.

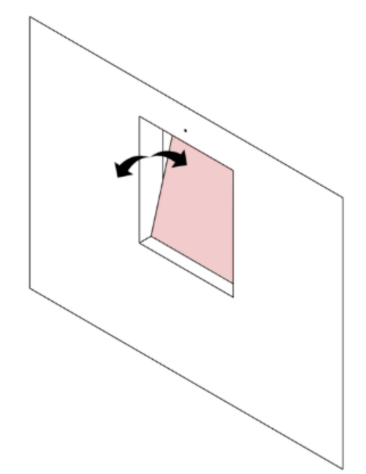

Figure 4. Schematic representation of an automation-based strategy enabling NV.

A different solution, still at a concept stage, has been recently proposed by Fusaro et al. [103], in which an origami acoustic metacage is used as a tunable device that can provide different ventilation and sound control performance in the folded and unfolded state. From the first analysis, the frequency and bandwidth in which the device is effective in controlling sound radiation resulted to depend on geometric and dimensional parameters [103].

Generally, automated façade solutions are currently mainly driven by thermal, lighting, or air quality sensors and not commonly adopted in combination with acoustic sensors. Automated strategies based on sound level thresholds driving the control logics seem to be limited by the need for non-steady outdoor acoustic conditions and by the availability of silent and quickly responsive opening mechanisms. This may justify the limited interest in research to investigate and develop such solutions. 


\subsection{Hybrid Strategies}

As stressed by De Salis et al., many of the above mentioned solutions can be integrated into hybrid techniques, able to combine the attenuation capabilities over different frequency bands in order to reach broadband attenuation [19]. As an example, Murao et al. recently investigated the attenuation capabilities of a hybrid system composed of an ANC system integrated with splitter silencers, inserted within a window opening. While silencers contributed to noise attenuation above $2 \mathrm{k} \mathrm{Hz}$, ANC attenuated the remaining medium-low frequency range, achieving a global attenuation of 2 to $17 \mathrm{~dB}$ over $200 \mathrm{~Hz}$, although at a cost of a strong opening obstruction.

\section{Limits in Current Approach towards Acoustic Comfort in Naturally Ventilated Buildings}

Limits and reference values provided by standards, design guidelines, and rating protocols for naturally ventilated residential buildings have been introduced in Section 2. Acoustic criteria have been based on indoor noise level reduction, typically without a distinction based on ventilation strategy. The normative context, in this way, requires buildings to guarantee silent indoor acoustic environments, without considering how to fulfil the acoustic requirements when multiple indoor environmental quality (IEQ) needs must be met.

As reviewed in Section 3, research has been committed to investigate several passive, active, automation-based, and hybrid solutions, aimed at satisfying the following needs: (i) maximizing noise abatement to allow for standard limits to be met, (ii) minimizing airflow resistance, (iii) guaranteeing adequate ventilation areas, while (iv) avoiding the obstruction of window view. Even if research on this topic is continuously ongoing and some solutions seem to be more promising than others, currently, none of the reviewed techniques fully satisfy the stated needs and none have been adopted on a large scale.

Two main factors seem to be present behind this apparent conflict between indoor acoustic comfort and natural ventilation, namely:

- A fragmented approach towards IEQ;

- The lack of a perceptual perspective.

The two criticalities are showed in Figure 1 in relation to the paper's structures and will be further discussed in the following paragraphs.

\subsection{A Fragmented Approach towards IEQ}

The fragmented approach towards IEQ has led standards, technical guidelines, and rating protocols to set acoustic design criteria that do not take into account how buildings are designed and operated to meet multiple needs that refer to areas of comfort other than acoustics (i.e., thermal, visual and indoor air quality).

As stressed by Field, acoustic criteria often make the adoption of NV unfeasible, because it is more difficult to meet the required noise limits than in the case of sealed and mechanically ventilated buildings $[104,105]$. Specific values for natural ventilated buildings are usually not present, except for the Green Star protocol that allows for higher indoor noise levels to be reached [83].

The lack of a holistic approach towards IEQ also results in not considering that building users are usually exposed not to only single, but multiple environmental factors, simultaneously. Multisensory research addresses this issue by investigating interaction effects (i.e., addictive, synergistic, and antagonistic effects [106] or even synesthetic associations [107]), occurring between different environmental stimuli upon human perception and performance but this field of research is still not fully explored and, as such, not integrated into building design regulations and practice $[106,108,109]$.

The draft Acoustics Ventilation and Overheating Residential Design Guide appears to be a first important attempt to integrate different design needs into a technical guideline, taking into account the combined exposure of building users to noise and overheating. The AVO guide proposes higher noise limits from transportation sources in overheating conditions, by considering their temporary 
nature and by assuming the major noise tolerance that is supposed to appear in favor of additional cooling through ventilation devices $[81,110]$. As previously mentioned, these considerations are not supported by scientific evidence, and the authors stress the need for further research investigating the perception of the acoustic environment in combined exposure to noise and heat $[81,110]$.

\subsection{The Lack of a Perceptual Perspective}

A differentiation of acoustic criteria between mechanical and natural ventilated buildings has already been advocated in the literature, starting from an analogy with thermal comfort criteria [104,105]. Indeed, standards on thermal comfort provide different criteria and models, on the basis of "different thermal experiences, changes in clothing, availability of control, and shifts in occupant expectations" occurring in naturally ventilated buildings [111], that have led to the definition of the adaptive thermal comfort model [112-114]. Similarly, according to Field, a different noise sensitivity could be assumed under NV conditions, resulting in higher noise levels to be tolerated, because of the following: (i) a lower expectation of low noise levels, (ii) the appreciation of non-acoustic benefits and (iii) a different availability of control in comparison to mechanically ventilated buildings [104,105]. Although it is not in the scope of the document, the AVO guide states as well that "there are other benefits for occupants from opening windows, such as the connection with the outside, sense of fresh air and perception of draughts when overheating, and sense of control over one's environment" [79]. Only through a perceptual perspective it would be possible to capture a broader picture over the complex user-building interaction occurring under NV conditions. Because it is currently only supported by anecdotal evidence, the existence of an "adaptive acoustic comfort" [115] model is worth further investigation by the research community to define acoustic criteria taking into account the multiple cognitive and behavioral factors impinging on comfort in naturally ventilated residential buildings.

Currently, acoustic design criteria and design strategies for façade devices reflect a general effort of minimizing noise annoyance by reducing noise exposure and, consequently, sound levels. The literature has already reported numerous criticisms on the effectiveness of decibel-based metrics in fully characterizing perceived sound quality (e.g., pleasantness ratings) [51]. Indeed, reducing noise levels do not always lead straightforwardly to an improved comfort or quality of life, as sounds and even loudness can be desirable in some contexts $[47,51,116]$. Aspects related to the nature of sounds and to their spectral and temporal composition have been found to significantly affect perceived sound quality [51]. The picture is even more complex if factors unrelated to the acoustic environment are considered [51].

That is to say, the mere use of higher sound level limits according to an "adaptive acoustic comfort" model is not enough to define acoustic criteria tailored to users' perception in naturally ventilated buildings. In order to assess the effectiveness of façade strategies to satisfy ventilation and acoustic needs, a perceptual perspective should be undertaken. Subjective assessment methods and objective metrics should consider how building users perceive the acoustic environment in order to understand what sound good to them. This is the goal of soundscape research.

\section{Rethinking NV for Positive Acoustic Alliesthesia under the Indoor Soundscape Approach}

The word "alliesthesia" means "changed sensation" and was coined by Cabanac [117] to express that a given stimulus, "can arouse different sensations according to the stimulated person's internal state: pleasant when useful and unpleasant when useless or harmful" [118]. The concept was then revisited by De Dear, as the logical framework for the adaptive thermal comfort model [6]. Basically, "a peripheral thermal sensation can assume either positive or negative hedonic tone, depending on the state of core temperature in relation to its thermo neutral set point" [5]. That is to say, for example, in warm and humid environments, air motion on occupants' skin surface provided through natural ventilation can be felt as pleasant by building occupants (i.e., generating "positive thermal alliesthesia"). On the contrary, "cool, dry, still indoor air" conditions guaranteed by sealed façades and mechanically controlled environments, designed according to the traditional Fanger's comfort model [119], are able 
to provide, at best, occupants with thermal neutral conditions (the so-called "thermal boredom" [5]) and above all else at a much higher energy consumption [6].

Although the alliesthesia concept originally referred to thermal, smell, and taste sensations, Cabanac later investigated its application also in the case of audiovisual stimuli and concluded that alliesthesia seems to occur with any sensation and this "tends to confirm the primordial place of pleasure as a motivation that triggers useful behaviors" [118]. Exploiting the hedonic potential of sounds according to building users' perception in context is indeed the goal of the soundscape approach. When applied to NV, such knowledge suggests that there may be room for NV devices to generate positive indoor soundscapes.

Despite the inherent differences between thermal and acoustic stimuli and their integration by people through different psychological, physiological, and neural mechanisms, such analogy seems interestingly to suggest the opportunity for $\mathrm{NV}$ to provide both thermally pleasant environments and positive indoor soundscape (or, in other words, positive "thermal and acoustic alliesthesia").

It must be observed that NV should never expose building occupants to harmful noise levels, even in the case of "pleasurable" indoor soundscapes, as noise exposure has been widely proven to be a risk for human health and well-being. Indeed, the Environmental Noise Guidelines for the European Region provided outdoor noise limits, based on established exposure-response relationships between the environmental noise (road traffic, railway, aircraft, wind turbines, and leisure events) and the proportion of people with a health outcome (i.e., increased risk of ischemic heart disease, hypertension, annoyance, sleep disturbance, impaired reading skills and oral comprehension in children, hearing impairment and tinnitus, and mental health and well-being) [25]. Interestingly, annoyance, rather than health outcomes, was the limiting factor for the provided environmental noise limits [51]. This observation suggests that higher noise level limits could be actually allowed and considered in the case of low-annoying acoustic environments, without harmful health-related effects on people. However, evidence provided by the WHO guidelines could be considered someway incomplete as it reflects a dose-response approach based on negative health outcomes (e.g., noise annoyance) and dB noise levels. By going beyond noise annoyance reduction and sound level minimization, a broader picture could be captured on perceptual and health outcomes resulting from the experience of the acoustic environment. Accordingly, the literature has reported that, in addition to health risks reduction, even positive-related health effects may result from acoustic environments being positively perceived by people $[47,64,120]$. Understanding the potential of a positive acoustic experience to enhance building users' health and well-being requires a perceptual, soundscape perspective to be adopted in order to comprehend what makes an acoustic environment sound "positive".

Rethinking NV under the indoor soundscape framework means to value it as a strategy to transmit, block or adjust outdoor sounds to provide a connection with the outside, release wanted sounds, or mask unwanted ones, while enabling low-cost and low-energy cooling and ventilation. In this way, the indoor soundscape approach changes the needs that NV solutions are required to meet, and the way in which those solutions are assessed.

Façade control strategies enabling NV should be assessed through the application of multiple perception-driven assessment methods, through triangulation. Techniques belonging to noise-control engineering and building acoustics should be coupled with soundscape assessment methods derived and adapted from urban studies. Exploring the hedonic potential of sounds released by ventilation devices requires the evaluation of a variety of auditory sensations besides annoyance [51]. Enquired categories for residential buildings could be related to the overall evaluation of the acoustic environment, the sound awareness and noticeability, sound preference, soundscape dimensions, sound-quality descriptors and the perception of control over the acoustic environment. The impact of a sense of control over the acoustic environment provided by the NV device (e.g., window opening and closing) should be carefully taken into account, and contact with the outside provided by the ventilation devices should also be better understood and considered. 
By coupling subjective measures with a set of objective acoustic and psychoacoustic parameters, i.e., neural and physiological measurements, it would be possible to guide the design of naturally ventilated buildings and of ventilation devices, taking into account people's perceptual and behavioral response to the acoustic environment. This also aligns with a salutogenic approach to building design, where the focus is more on "peoples' resources and capacity to create health than the classic focus on risks, ill health, and disease" [46].

Furthermore, the interaction between acoustic and other environmental stimuli should be investigated in terms of user perceptual response, and user-building interactions. This is indeed part of the indoor soundscape framework, because environmental factors together with urban context and building characteristics, personal traits, socioeconomic features, and situational circumstances are considered to characterize the context in which the acoustic perception occurs.

\section{Suggestions for the Research Agenda}

The assessment of façade control strategies enabling NV should rely on methods able to describe their impact on the physical acoustic environment and on the perception of the building users, depending on the specific context of application.

Because of current gaps in indoor soundscape research, as stressed in Section 2, further efforts are deemed necessary in order to define:

- Indoor soundscape descriptors, able to describe the perception of the indoor acoustic environment according to relevant perceptual dimensions peculiar of indoor spaces;

- Indoor soundscape indicators, integrating sound level metrics, psychoacoustic, and room and building acoustic parameters eventually within new indices, in order to predict the indoor soundscape descriptors.

Soundscape descriptors and indicators should be derived from laboratory or field studies taking into account the peculiarities of indoor soundscapes as compared with outdoor ones, such as:

- The presence of multiple outdoor-generated sounds combined with sounds generated indoor, both into the space where the perception occurs or in adjacent spaces (e.g., sounds from neighbors);

- The presence of a reverberant field;

- The specific task, depending on the building type or on the building area.

In addition to this, when evaluating the effectiveness of NV devices in providing positive indoor soundscapes, specific cognitive and behavioral factors underpinning acoustic comfort in naturally ventilated buildings should be addressed and better understood by future research, such as:

- The perceived control over the acoustic environment;

- The provided contact with outside;

- People response in the presence of multiple environmental factors.

Perceived control over the acoustic conditions at home was reported in literature as a factor mediating the association between the acoustic conditions and the perceptual outcomes $[121,122]$. If the perception of control over one's own environment is already of paramount importance in thermal comfort theory, understanding its impact on acoustic comfort in naturally ventilated buildings would be fruitful to value this benefit of NV and to "measure" how different ventilation technologies contribute to it.

The provided contact with the outside is often mentioned as a beneficial side effect of NV. Further empirical evidence is needed in order to understand how this factor mediates in the definition of thermal, visual, acoustic, and air quality comfort conditions for building users. Such knowledge would allow for exploit NV and the sounds released through ventilation devices in order to create contact with the external environment and nature, depending on the specific context, according also to biophilic design strategies [123]. 
Interaction effects and synesthetic associations on perception in the presence of multiple environmental factors should be further explored, both in the laboratory and in real-life assessments, specifically in relation to overheating or breeze conditions. Such multisensory research could lead to a better understanding of comfort perception under different environmental conditions (e.g., change in thermal comfort perception under positive indoor soundscapes or change in acoustical comfort perception under increased air speed for cooling reasons in overheating conditions).

\section{Conclusions}

This concept paper has reported on the application of the indoor soundscape approach to the research field of acoustic comfort in naturally ventilated residential buildings. In this study, the following three questions were raised: (i) What does the indoor soundscape conceptual framework represent? (ii) What limits can be identified in the current approach towards acoustic comfort under NV conditions in residential buildings? and (iii) How can the highlighted limits be overcome by the application of the indoor soundscape approach to the NV context?

With respect to the first research question, the indoor soundscape framework has been introduced by referring to the most recent research. Indoor soundscape characterizes how people perceive, experience, and understand the indoor acoustic environment in the context of their working, living or leisure environments, with the aim of designing positively perceived indoor acoustic environments. As compared with the soundscape concept, as originally investigated and developed from urban studies, the building itself plays a fundamental role in defining the three pillars of the indoor soundscape concept. Indeed, the building enclosure demarcates the boundary and the connections between the indoor and the outdoor (i.e., "context"), depending on its geometry and materials, it filters outdoor sounds and shapes the indoor acoustic environment (i.e., "acoustic environment"), and depending on its function, it contributes to building users" expectations and needs ("people").

Acoustic criteria required for naturally ventilated residential buildings have been reviewed, and a summary of the façade noise control solutions developed so far to meet those criteria have been provided. Acoustic criteria were found to be based on indoor noise level reduction, typically without a distinction based on ventilation strategy.

With respect to the second research question, the outcomes of the analysis indicated two main limits. First, a fragmented view towards indoor environmental quality has resulted in acoustic criteria that does not consider how buildings are designed and operated to meet multiple needs other than acoustical ones (e.g., ventilation, visual, and cooling needs) and how people respond to multiple simultaneous environmental stimuli. Secondly, the lack of a perceptual perspective has resulted in acoustic criteria that neglects the multiple cognitive and behavioral factors impinging on comfort in naturally ventilated residential buildings. The literature suggested that factors such as the connection with the outside and the sense of control over one's environment may induce "adaptive acoustic comfort" opportunities, but these aspects need to be further addressed by the research community to find scientific evidence. In any case, the mere use of sound level limits is not enough to reflect the acoustic perception of indoor environments and this suggests the inadequacy of their use to define criteria tailored to the complex user-building interaction that can occur under NV conditions.

With respect to the third research question, the discussion suggested that under the indoor soundscape perspective there seems to be a potential to solve the current apparent conflict between ventilation and acoustic needs impeding the adoption of NV strategies on a large scale. In fact, by underpinning a perceptual perspective (the "people" pillar) and by contextualizing the perceptual experience (the "context" pillar), the indoor soundscape appears to be a framework able to overcome the underlined current limits. Rethinking NV under the indoor soundscape framework means to value it as a strategy to transmit, block or adjust outdoor sounds in order to provide a connection with the outside, release wanted sounds or mask unwanted sounds.

The design implication of the indoor soundscape approach reflects a paradigm shift from controlling noise levels as the only comfort parameter in residential buildings, to exploiting sounds as 
a resource to generate positive indoor soundscapes or, in other words, "positive acoustic alliesthesia". This could give designers and acousticians a much wider palette of comfort solutions related to multiple disciplines that could be applied differently according to people and to their context. The main challenge is to provide comprehensive scientific evidence that associates neural, physiological, psychological, and contextual factors with (psycho) acoustical indices, able to guide the design of positive indoor residential soundscapes, also thanks to NV.

Taken together, this analysis encourages research efforts to integrate soundscape methodologies into the indoor environmental quality research, with the final goal of fostering the adoption of NV as a passive design strategy able to enhance user health and well-being, while enabling low-cost and low-energy cooling and ventilation, and thus contributing to current climate change challenges.

Author Contributions: Conceptualization, S.T., R.A., F.A., F.B., T.O. and J.K.; methodology, S.T., R.A., F.A., F.B., T.O. and J.K.; writing—original draft preparation, S.T.; writing—review, S.T., R.A., F.A., F.B., T.O. and J.K.

Funding: This research was funded by the "Programma di cooperazione Interreg V-A Italia-Svizzera 2014-2020", project "QAES" ID no. 613474. F.A., T.O. and J.K. have received funding from the European Research Council (ERC) under the European Union's Horizon 2020 research and innovation programme (grant agreement No. 740696).

Conflicts of Interest: The authors declare no conflict of interest.

\section{References}

1. Tong, Z.; Chen, Y.; Malkawi, A.; Liu, Z.; Freeman, R.B. Energy saving potential of natural ventilation in China: The impact of ambient air pollution. Appl. Energy 2016, 179, 660-668. [CrossRef]

2. Brager, G.; Zhang, H.; Arens, E. Evolving opportunities for providing thermal comfort. Build. Res. Inf. 2015, 43, 274-287. [CrossRef]

3. Rasheed, E.O.; Byrd, H. Can a naturally ventilated office outperform a mixed mode office? Pilot study on occupants' comfort. Build. Environ. 2018, 137, 34-40. [CrossRef]

4. Tong, Z.; Chen, Y.; Malkawi, A. Estimating natural ventilation potential for high-rise buildings considering boundary layer meteorology. Appl. Energy 2017, 193, 276-286. [CrossRef]

5. Candido, C.; De Dear, R. From thermal boredom to thermal pleasure: A brief literature review. Ambient. Construído 2012, 12, 81-90. [CrossRef]

6. De Dear, R. Revisiting an old hypothesis of human thermal perception: Alliesthesia. Build. Res. Inf. 2011, 39, 108-117. [CrossRef]

7. Seppänen, O.; Fisk, W.J. Association of ventilation system type with SBS symptoms in office workers. Indoor Air 2002, 12, 98-112. [CrossRef]

8. Mendell, M.J.; Fisk, W.J.; Kreiss, K.; Levin, H.; Alexander, D.; Cain, W.S.; Girman, J.R.; Hines, C.J.; Jensen, P.A.; Milton, D.K.; et al. Improving the health of workers in indoor environments: Priority research needs for a national occupational research agenda. Am. J. Public Health 2002, 92, 1430-1440. [CrossRef]

9. Linden, P.F. The fluid mechanics of natural ventilation. Annu. Rev. Fluid Mech. 1999, 31, 201-238. [CrossRef]

10. Etheridge, D. Natural Ventilation of Buildings: Theory, Measurement and Design; WILEY: Hoboken, NJ, USA, 2011.

11. Shetabivash, H. Investigation of opening position and shape on the natural cross ventilation. Energy Build. 2015, 93, 1-15. [CrossRef]

12. Gao, C.F.; Lee, W.L. Evaluating the influence of openings configuration on natural ventilation performance of residential units in Hong Kong. Build. Environ. 2011, 46, 961-969. [CrossRef]

13. Asfour, O.S. Effect of building plan form on human thermal comfort in naturally ventilated open-plan enclosures located in hot climates. J. Green Build. 2017, 12, 112-129. [CrossRef]

14. Ramponi, R.; Gaetani, I.; Angelotti, A. Influence of the urban environment on the effectiveness of natural night-ventilation of an office building. Energy Build. 2014, 78, 25-34. [CrossRef]

15. Chen, Y.; Tong, Z.; Malkawi, A. Investigating natural ventilation potentials across the globe: Regional and climatic variations. Build. Environ. 2017, 122, 386-396. [CrossRef]

16. Chen, J.; Brager, G.S.; Augenbroe, G.; Song, X. Impact of outdoor air quality on the natural ventilation usage of commercial buildings in the US. Appl. Energy 2019, 235, 673-684. [CrossRef] 
17. Costanzo, V.; Yao, R.; Xu, T.; Xiong, J.; Zhang, Q.; Li, B. Natural ventilation potential for residential buildings in a densely built-up and highly polluted environment. A case study. Renew. Energy 2019, 138, 340-353. [CrossRef]

18. Barclay, M.; Kang, J.; Sharples, S. Combining noise mapping and ventilation performance for non-domestic buildings in an urban area. Build. Environ. 2012, 52, 68-76. [CrossRef]

19. De Salis, M.H.F.; Oldham, D.J.; Sharples, S. Noise control strategies for naturally ventilated buildings. Build. Environ. 2002, 37, 471-484. [CrossRef]

20. Tang, S.-K. A Review on Natural Ventilation-enabling Façade Noise Control Devices for Congested High-Rise Cities. Appl. Sci. 2017, 7, 175. [CrossRef]

21. Huang, H.; Qiu, X.; Kang, J. Active noise attenuation in ventilation windows. J. Acoust. Soc. Am. 2011, 130, 176-188. [CrossRef]

22. Kang, J. An acoustic window system with optimum ventilation and daylighting performance. Noise Vib. Worldw. 2006, 37, 9-17. [CrossRef]

23. Zuccherini Martello, N.; Aletta, F.; Fausti, P.; Kang, J.; Secchi, S. A Psychoacoustic Investigation on the Effect of External Shading Devices on Building Facades. Appl. Sci. 2016, 6, 429. [CrossRef]

24. Fausti, P.; Secchi, S.; Zuccherini Martello, N. The use of façade sun shading systems for the reduction of indoor and outdoor sound pressure levels. Build. Acoust. 2019, 26, 181-206. [CrossRef]

25. WHO. Environmental Noise Guidelines For The European Region; WHO: Copenhagen, Denmark, 2018.

26. Guski, R.; Schreckenberg, D.; Schuemer, R. WHO environmental noise guidelines for the European region: A systematic review on environmental noise and annoyance. Int. J. Environ. Res. Public Health 2017, 14, 1539. [CrossRef]

27. Morel, J.; Marquis-Favre, C.; Viollon, S.; Alayrac, M. A laboratory study on total noise annoyance due to combined industrial noises. Acta Acust. United Acust. 2012, 98, 286-300. [CrossRef]

28. Pierrette, M.; Marquis-Favre, C.; Morel, J.; Rioux, L.; Vallet, M.; Viollon, S.; Moch, A. Corrigendum to "Noise annoyance from industrial and road traffic combined noises: A survey and a total annoyance model comparison"[J Environ Psychol 32 (2)(2012) 178-186]. J. Environ. Psychol. 2012, 3, 285. [CrossRef]

29. Pierrette, M.; Marquis-Favre, C.; Morel, J.; Rioux, L.; Vallet, M.; Viollon, S.; Moch, A. Noise annoyance from industrial and road traffic combined noises: A survey and a total annoyance model comparison. J. Environ. Psychol. 2012, 32, 178-186. [CrossRef]

30. Marquis-Favre, C.; Premat, E.; Aubrédue, D. Noise and its effects-A review on qualitative aspects of sound. Part II: Noise and annoyance. Acta Acust. United Acust. 2005, 91, 626-642.

31. Morel, J.; Marquis-Favre, C.; Gille, L.A. Noise annoyance assessment of various urban road vehicle pass-by noises in isolation and combined with industrial noise: A laboratory study. Appl. Acoust. 2016, 101, 47-57. [CrossRef]

32. Steinbach, L.; Altinsoy, M.E. Prediction of annoyance evaluations of electric vehicle noise by using artificial neural networks. Appl. Acoust. 2019, 145, 149-158. [CrossRef]

33. Klein, A.; Marquis-Favre, C.; Weber, R.; Trollé, A. Spectral and modulation indices for annoyance-relevant features of urban road single-vehicle pass-by noises. J. Acoust. Soc. Am. 2015, 137, 1238-1250. [CrossRef] [PubMed]

34. Bravo-Moncayo, L.; Lucio-Naranjo, J.; Chávez, M.; Pavón-García, I.; Garzón, C. A machine learning approach for traffic-noise annoyance assessment. Appl. Acoust. 2019, 156, 262-270. [CrossRef]

35. Klein, A.; Marquis-Favre, C.; Champelovier, P. Assessment of annoyance due to urban road traffic noise combined with tramway noise. J. Acoust. Soc. Am. 2017, 141, 231-242. [CrossRef] [PubMed]

36. Gille, L.-A.; Marquis-Favre, C. Estimation of field psychoacoustic indices and predictive annoyance models for road traffic noise combined with aircraft noise. J. Acoust. Soc. Am. 2019, 145, 2294-2304. [CrossRef] [PubMed]

37. Jik Lee, P.; Griffin, M.J. Combined effect of noise and vibration produced by high-speed trains on annoyance in buildings. J. Acoust. Soc. Am. 2013, 133, 2126-2135. [CrossRef] [PubMed]

38. Vallin, P.-A.; Marquis-Favre, C.; Bleuse, J.; Gille, L.-A. Railway noise annoyance modeling: Accounting for noise sensitivity and different acoustical features. J. Acoust. Soc. Am. 2018, 144, 3381-3390. [CrossRef] [PubMed] 
39. Trollé, A.; Marquis-Favre, C.; Klein, A. Short-term annoyance due to tramway noise: Determination of an acoustical indicator of annoyance via multilevel regression analysis. Acta Acust. United Acust. 2014, 100, 34-45. [CrossRef]

40. Alayrac, M.; Marquis-Favre, C.; Viollon, S. Total annoyance from an industrial noise source with a main spectral component combined with a background noise. J. Acoust. Soc. Am. 2011, 130, 189-199. [CrossRef]

41. Alayrac, M.; Marquis-Favre, C.; Viollon, S.; Morel, J.; Le Nost, G. Annoyance from industrial noise: Indicators for a wide variety of industrial sources. J. Acoust. Soc. Am. 2010, 128, 1128-1139. [CrossRef]

42. Taghipour, A.; Pieren, R.; Schäffer, B. Short-term annoyance reactions to civil helicopter and propeller-driven aircraft noise: A laboratory experiment. J. Acoust. Soc. Am. 2019, 145, 956-967. [CrossRef]

43. ISO. ISO 12913-1:2014-Acoustics-Soundscape Part 1: Definition and Conceptual Framework; ISO: Geneva, Switzerland, 2014.

44. Kang, J.; Aletta, F.; Gjestland, T.T.; Brown, L.A.; Botteldooren, D.; Schulte-Fortkamp, B.; Lercher, P.; van Kamp, I.; Genuit, K.; Fiebig, A.; et al. Ten questions on the soundscapes of the built environment. Build. Environ. 2016, 108, 284-294. [CrossRef]

45. Antonovsky, A. Health, Stress, and Coping; Jossey-Bass: San Francisco, CA, USA, 1979.

46. Lindstroem, B.; Eriksson, M. Salutogenesis. J. Epidemiol. Community Health 2005, 59, 440-442. [CrossRef] [PubMed]

47. Aletta, F.; Oberman, T.; Kang, J. Associations between positive health-related effects and soundscapes perceptual constructs: A systematic review. Int. J. Environ. Res. Public Health 2018, 15, 2392. [CrossRef] [PubMed]

48. Kang, J.; Aletta, F.; Oberman, T.; Erfanian, M.; Kachlicka, M.; Lionello, M.; Mitchell, A. Towards soundscape indices. In Proceedings of the International Congress on Acoustics-ICA, Aachen, Germany, 9-13 September 2019; pp. 2488-2495.

49. ISO. ISO TS 12913-2:2018-Acoustics—Soundscape Part 2: Data Collection and Reporting Requirements; ISO: Geneva, Switzerland, 2018.

50. Aletta, F.; Astolfi, A. Soundscapes of buildings and built environments. Build. Acoust. 2018, 25, $195-197$. [CrossRef]

51. Torresin, S.; Albatici, R.; Aletta, F.; Babich, F.; Kang, J. Assessment methods and factors determining positive indoor soundscapes in residential buildings: A systematic review. Sustainability 2019, 11, 5290. [CrossRef]

52. Ercakmak, U.B.; Nur, P.; Yorukoglu, D. The role of indoor soundscape methodology: From architectural design process to establishment of regulations. In Proceedings of the International Congress on Acoustics-ICA, Aachen, Germany, 9-13 September 2019; pp. 4160-4167.

53. Dokmeci Yorukoglu, P.N.; Kang, J. Analysing sound environment and architectural characteristics of libraries through indoor soundscape framework. Arch. Acoust. 2016, 41, 203-212. [CrossRef]

54. Aburawis, A.A.M.; Dokmeci Yorukoglu, P.N. An integrated framework on soundscape perception and spatial experience by adapting post-occupancy evaluation methodology. Build. Acoust. 2018, 25, 3-16. [CrossRef]

55. Ercakmak, U.B.; Dokmeci Yorukoglu, P.N. Comparing Turkish and European Noise Management and Soundscape Policies: A Proposal of Indoor Soundscape Integration to Architectural Design and Application. Acoustics 2019, 1, 847-865. [CrossRef]

56. Dokmeci Yorukoglu, P.N.; Kang, J. Development and testing of indoor soundscape questionnaire for evaluating contextual experience in public spaces. Build. Acoust. 2017, 24, 307-324. [CrossRef]

57. Berglund, B.; Nilsson, M.E. On a tool for measuring soundscape quality in urban residential areas. Acta Acust. United Acust. 2006, 92, 938-944.

58. Dokmeci, P.N.; Kang, J. Indoor soundscape analysis of enclosed public and commercial spaces with soundwalk method. In Proceedings of the Inter-Noise 2012 - 41rd International Congress on Noise Control Engineering, New York, NY, USA, 19-22 August 2012; p. 8.

59. Ma, K.W.; Wong, H.M.; Mak, C.M. A systematic review of human perceptual dimensions of sound: Meta-analysis of semantic differential method applications to indoor and outdoor sounds. Build. Environ. 2018, 133, 123-150. [CrossRef]

60. Acun, V.; Yilmazer, S. A grounded theory approach to investigate the perceived soundscape of open-plan offices. Appl. Acoust. 2018, 131, 28-37. [CrossRef]

61. Yilmazer, S.; Acun, V. A grounded theory approach to assess indoor soundscape in historic religious spaces of Anatolian culture: A case study on Hacı Bayram Mosque. Build. Acoust. 2018, 25, 137-150. [CrossRef] 
62. Acun, V.; Yilmazer, S. Combining grounded theory (GT) and structural equation modelling (SEM) to analyze indoor soundscape in historical spaces. Appl. Acoust. 2019, 155, 515-524. [CrossRef]

63. Mohamed, M.A.E.; Dokmeci Yorukoglu, P.N. Indoor soundscape perception in residential spaces: A cross-cultural analysis in Ankara, Turkey. Build. Acoust. 2019, 1351010X19885030. [CrossRef]

64. Ma, H.; Shu, S. An Experimental study: The restorative effect of soundscape elements in a simulated open-plan office. Acta Acust. United Acust. 2018, 104, 106-115. [CrossRef]

65. Xiao, J.; Aletta, F. A soundscape approach to exploring design strategies for acoustic comfort in modern public libraries: A case study of the Library of Birmingham. Noise Mapp. 2016, 3, 264-273. [CrossRef]

66. Aletta, F.; Botteldooren, D.; Thomas, P.; Vander Mynsbrugge, T.; De Vriendt, P.; Van de Velde, D.; Devos, P. Monitoring Sound levels and soundscape quality in the living rooms of nursing homes: A case study in Flanders (Belgium). Appl. Sci. 2017, 7, 874. [CrossRef]

67. Mackrill, J.; Cain, R.; Jennings, P. Experiencing the hospital ward soundscape: Towards a model. J. Environ. Psychol. 2013, 36, 1-8. [CrossRef]

68. Thomas, P.; Aletta, F.; Filipan, K.; Vander Mynsbrugge, T.; De Geetere, L.; Dijckmans, A.; Botteldooren, D.; Petrovic, M.; Van de Velde, D.; De Vriendt, P.; et al. Noise environments in nursing homes: An overview of the literature and a case study in Flanders with quantitative and qualitative methods. Appl. Acoust. 2020, 159, 107103. [CrossRef]

69. Acun, V.; Yilmazer, S. Understanding the indoor soundscape of study areas in terms of users' satisfaction, coping methods and perceptual dimensions. Noise Control Eng. J. 2018, 66, 66-75. [CrossRef]

70. Lindborg, P. Psychoacoustic, physical, and perceptual features of restaurants: A field survey in Singapore. Appl. Acoust. 2015, 92, 47-60. [CrossRef]

71. Meng, Q.; Kang, J. Influence of social and behavioural characteristics of users on their evaluation of subjective loudness and acoustic comfort in shopping malls. PLoS ONE 2013, 8, e54497. [CrossRef] [PubMed]

72. Chen, B.; Kang, J. Acoustic Comfort in Shopping Mall Atrium Spaces - A Case Study in Sheffield Meadowhall Acoustic Comfort in Shopping Mall Atrium Spaces A Case Study in Sheffield Meadowhall. Archit. Sci. Rev. 2004, 47, 107-114. [CrossRef]

73. Yilmazer, S.; Bora, Z. Understanding the indoor soundscape in public transport spaces: A case study in Akköprü metro station, Ankara. Build. Acoust. 2017, 24, 325-339. [CrossRef]

74. EN. BS-EN 16798-1:2019 Energy Performance of Buildings_Ventilation for Buildings_Part 1: Indoor Environmental Input Parameters for Design and Assessment of Energy Performance of Buildings Addressing Indoor Air Quality, Thermal Environment, Lighting and Acousitics; EN: Bruxelles, Belgium, 2019.

75. AS/NZS. AS/NZS 2107:2016 Acoustics—Recommended Design Sound Levels and Reverberation Times for Building Interiors; AS: Vienna, Austria, 2016.

76. BS. BS 8233: 2014 Guidance on Sound Insulation and Noise Reduction for Buildings; BS: London, UK, 2014.

77. Berglund, B.; Lindvall, T.; Schwela, D.H.; WHO Organization. Guidelines for Community Noise; WHO: Geneva, Switzerland, 1999.

78. ASHRAE. ANSI/ASHRAE/ICC/USGBC/IES Addendum o to ANSI/ASHRAE/USGBC/IES Standard 189.1-2014-Standard for the Design of High-Performance Green Buildings. Except Low-Rise Green Buildings; American Society of Heating, Refrigerating and Air-Conditioning Engineers: Atlanta, GA, USA, 2017.

79. ANC. Acoustics Ventilation and Overheating Residential Design Guide DRAFT COPY for Consultation-issued February 2018; ANC: Croydon, UK, 2018.

80. Chartered Institution of Building Services Engineers CIBSE. Guide A. Environmental Design; CIBSE: London, UK, 2015.

81. Harvie-Clark, J.; Chilton, A.; Conlan, N.; Trew, D. Assessing noise with provisions for ventilation and overheating in dwellings. Build. Serv. Eng. Res. Technol. 2019, 40, 263-1273. [CrossRef]

82. BREEAM International New Construction 2016. Available online: https://www.breeam.com/ BREEAMInt2016SchemeDocument/\#resources/output/10_pdf/a4_pdf/nc_pdf_printing/sd233_nc_int_ 2016_print.pdf (accessed on 18 April 2019).

83. Greenstar. Green Star-Design E As Built V1.2-Submission Guidelines; Green Building Council of Australia: Sydney, NSW, Australia, 2015.

84. HQM ONE. Home Quality Mark ONE. Available online: http://www.homequalitymark.com/filelibrary/ Manuals/HQM-ONE-Technical-Manual--SD239-.pdf (accessed on 18 April 2019). 
85. LEED. v4.1 Residential Single Family Homes. Available online: https://build.usgbc.org/singlefamilyclean41 (accessed on 18 April 2019).

86. LEED. v4.1 Residential BD+C Multifamily Homes. Available online: https://build.usgbc.org/multifamclean41 (accessed on 18 April 2019).

87. WELL. v2. Sound. Available online: https://v2.wellcertified.com/v/en/sound (accessed on 18 April 2019).

88. WELL Performance Verification Guidebook. Available online: https://www.wellcertified.com/sites/default/ files/resources/WELL\%20Performance\%20Verification\%20Guidebook\%20Q4.pdf (accessed on 18 April 2019).

89. Yu, X.; Lu, Z.; Cheng, L.; Cui, F. On the sound insulation of acoustic metasurface using a sub-structuring approach. J. Sound Vib. 2017, 401, 190-203. [CrossRef]

90. Yu, X. Design and in-situ measurement of the acoustic performance of a metasurface ventilation window. Appl. Acoust. 2019, 152, 127-132. [CrossRef]

91. Biler, A.; Tavil, A.U.; Su, Y.; Khan, N. A review of performance specifications and studies of trickle vents. Buildings 2018, 8, 152. [CrossRef]

92. Sharpe, T.; Farren, P.; Howieson, S.; Tuohy, P. Occupant interactions and effectiveness of natural ventilation strategies in contemporary new housing in Scotland, UK. Int. J. Environ. Res. Public Health 2015, 12, 8480-8497. [CrossRef]

93. Yu, X.; Lau, S.K.; Cheng, L.; Cui, F. A numerical investigation on the sound insulation of ventilation windows. Appl. Acoust. 2017, 117, 113-121. [CrossRef]

94. Kang, J.; Brocklesby, M.W. Feasibility of applying micro-perforated absorbers in acoustic window systems. Appl. Acoust. 2005, 66, 669-689. [CrossRef]

95. Kang, J.; Li, Z. Numerical simulation of an acoustic window system using finite element method. Acta Acust. United Acust. 2007, 93, 152-163.

96. Tang, S.K. Reduction of sound transmission across plenum windows by incorporating an array of rigid cylinders. J. Sound Vib. 2018, 415, 25-40. [CrossRef]

97. Urbán, D.; Roozen, N.B.; Zat'ko, P.; Rychtáriková, M.; Tomašovič, P.; Glorieux, C. Assessment of sound insulation of naturally ventilated double skin facades. Build. Environ. 2016, 110, 148-160. [CrossRef]

98. Lam, B.; Shi, C.; Shi, D.; Gan, W.S. Active control of sound through full-sized open windows. Build. Environ. 2018, 141, 16-27. [CrossRef]

99. Lam, B.; Elliott, S.; Cheer, J.; Gan, W.S. Physical limits on the performance of active noise control through open windows. Appl. Acoust. 2018, 137, 9-17. [CrossRef]

100. Wang, S.; Yu, J.; Qiu, X.; Pawelczyk, M.; Shaid, A.; Wang, L. Active sound radiation control with secondary sources at the edge of the opening. Appl. Acoust. 2017, 117, 173-179. [CrossRef]

101. Carme, C.; Schevin, O.; Romerowski, C.; Clavard, J. Active opening windows. In Proceedings of the ICSV 2016 - 23rd International Congress on Sound and Vibration: From Ancient to Modern Acoustics, Athens, Greece, 10-14 July 2016.

102. Martin, N.; Liebl, A.; Weber, L.; Dubovski, Z. Attentive windows-Noise-controlled window ventilation. Inst. Noise Control Eng. 2016, 253, 4906-4912.

103. Fusaro, G.; Yu, X.; Cui, F.; Kang, J. Development of a metamaterial for acoustic and architectonical improvement of window design. In Proceedings of the International Congress on Acoustics-ICA, Aachen, Germany, 9-13 September 2019; pp. 1977-1983.

104. Field, C.D.; Digerness, J. Acoustic design criteria for naturally ventilated buildings. Proceedings of Acoustics 08 Paris, Paris, France, 29 June-4 July; 2008.

105. Field, C.D. Acoustic design criteria for naturally ventilated buildings-unnnescessarily stringent? Forum Ecolibrium 2015, 4, 30-33.

106. Torresin, S.; Pernigotto, G.; Cappelletti, F.; Gasparella, A. Combined effects of environmental factors on human perception and objective performance: A review of experimental laboratory works. Indoor Air 2018, 28, 525-538. [CrossRef] [PubMed]

107. Ward, J.; Huckstep, B.; Tsakanikos, E. Sound-colour synaesthesia: To what extent does it use cross-modal mechanisms common to us all? Cortex 2006, 42, 264-280. [CrossRef]

108. ASHRAE. ASHRAE Guideline 10-2011-Interactions Affecting the Achievement of Acceptable Indoor Environments; ASHRAE: Atlanta, GA, USA, 2011.

109. Bluyssen, P.M. Towards an integrated analysis of the indoor environmental factors and its effects on occupants. Intell. Build. Int 2019, 1-9. [CrossRef] 
110. Chilton, A.; Healey, J.; Hyden, M.; Harvie-clark, J.; Trew, D.; Conlan, N. Design Guide for Noise, Ventilation and Over-Heating in Residential Developments. In Proceedings of the 24th International Congress on Sound and Vibration, London, UK, 23-27 July; 2017; pp. 1-8.

111. ASHRAE. Standard 55-2017 Thermal Environmental Conditions for Human Occupancy; ASHRAE: Atlanta, GA, USA, 2017.

112. De Dear, R.; Brager, G.S. Developing an adaptive model of thermal comfort and preference. ASHRAE Trans. 1998, 104, 1-18.

113. Nicol, J.F.; Humphreys, M.A. Adaptive thermal comfort and sustainable thermal standards for buildings. Energy Build. 2002, 34, 563-572. [CrossRef]

114. Parkinson, T.; de Dear, R.; Brager, G. Nudging the adaptive thermal comfort model. Energy Build. 2020, 206, 109559. [CrossRef]

115. Harvie-Clark, J.; Chilton, A.; Conlan, N.; Trew, D. Adaptive acoustic comfort: Assessing noise with provisions for ventilation and overheating in dwellings. In Proceedings of the 23rd International Conference of Acoustics, Aachen, North Rhine-Westphalia, Germany, 9-13 September; 2019.

116. Aletta, F.; Kang, J. Promoting Healthy and Supportive Acoustic Environments: Going beyond the Quietness. Int. J. Environ. Res. Public Health. 2019, 16, 4988. [CrossRef]

117. Cabanac, M. Physiological role of pleasure. Science 1971, 173, 1103-1107. [CrossRef]

118. Brondel, L.; Cabanac, M. Alliesthesia in visual and auditory sensations from environmental signals. Physiol. Behav. 2007, 91, 196-201. [CrossRef]

119. Fanger, P.O. Thermal comfort. Analysis and applications in environmental engineering. In Thermal Comfort. Analysis and Applications in Environmental Engineering; CAB Direct: Copenhaghen, Denmark, 1970.

120. Shu, S.; Ma, H. Restorative Effects of Classroom Soundscapes on Children's Cognitive Performance. Int. J. Environ. Res. Public Health 2019, 16, 293. [CrossRef]

121. Riedel, N.; Köckler, H.; Scheiner, J.; van Kamp, I.; Erbel, R.; Loerbroks, A.; Claßen, T.; Bolte, G. Home as a place of noise control for the elderly? A cross-sectional study on potential mediating effects and associations between road traffic noise exposure, access to a quiet side, dwelling-related green and noise annoyance. Int. J. Environ. Res. Public Health 2018, 15, 1036. [CrossRef] [PubMed]

122. Guski, R.; Felscher-Suhr, U.; Schuemer, R. The concept of noise annoyance: How international experts see it. J. Sound Vib. 1999, 223, 513-527. [CrossRef]

123. Kellert, S.R. Building for Life: Designing and Understanding the Human-Nature Connection; Island Press: Washington, DC, USA, 2012. 